\title{
Discrimination of young and mature leaves of Melicope ptelefolia using 1H NMR and multivariate data analysis
}

\begin{abstract}
The đ́llamô a traditional Malay dish, are plants that can be eaten raw, as a form of local salad. The shoots and young leaves of Melicope ptelefolia are among the popular species, believed to be high in nutritional and medicinal values. The metabolomic fingerprinting analysis of the ethanolic extracts of leaves of M. ptelefolia was carried out using $1 \mathrm{H}$ Nuclear Magnetic Resonance (NMR) spectroscopy and multivariate data analysis in order to differentiate young and mature leaves and to evaluate the variation of their chemical composition. Principle component analysis (PCA) of the 1H NMR spectra showed a clear discrimination between the young and mature leaves extracts by PC3 and PC4. The compounds responsible for the differentiation were identified by comparison of $1 \mathrm{H}$ NMR chemical shifts and qualitative HPLC. The young leaves were found to be richer in fatty acids and the levels of the three marker compounds, p-O-geranylcoumaric acid, 2,4,6-trihydroxy-3geranylacetophenone and 2,4,6-trihydroxy 3-prenylacetophenone, were clearly higher. The mature leaves contain higher levels of sugars and glycosidic components.
\end{abstract}

Keyword: Metabolomics; Multivariate data analysis; Principle component analysis; NMR; Melicope ptelefolia 